\title{
Reduction of the incidence of polyspermic penetration into porcine oocytes by pretreatment of fresh spermatozoa with adenosine and a transient co-incubation of the gametes with caffeine
}

\author{
Hiroaki Funahashi ${ }^{1}$ and Raquel Romar $^{1,2}$ \\ ${ }^{1}$ The Graduate School of Natural Science and Technology, Okayama University, Tsushima-naka, Okayama \\ 700-8530, Japan and ${ }^{2}$ Department of Physiology (Veterinary Physiology), Faculty of Veterinary Science, \\ Murcia University, 30071 Murcia, Spain \\ Correspondence should be addressed to H Funahashi; Email: hirofun@cc.okayama-u.ac.jp
}

\begin{abstract}
To reduce the incidence of polyspermic penetration, the effects of transient exposure of washed fresh spermatozoa to caffeine in a brief co-culture in vitro fertilization (IVF) system were examined. A pretreatment effect of spermatozoa with adenosine was also examined. When $5 \mathrm{mmol}$ caffeine/l was supplemented during periods of co-culture and additional culture periods until $8 \mathrm{~h}$ after insemination, a shortened co-incubation period of gametes (30 denuded oocytes in $100 \mu \mathrm{l}$ modified Medium 199-suspended spermatozoa at $2.5 \times 10^{5} \mathrm{sperm} / \mathrm{ml}$ ) from 30 to $5 \mathrm{~min}$ increased the monospermy rate in total mature oocytes examined. The number of spermatozoa binding to the zona surface was significantly lower in oocytes co-cultured for 5 min $(33.1 \pm 2.2)$ than $8 \mathrm{~h}(207.6 \pm 13.7)$. A limited exposure of gametes to $5 \mathrm{mmol}$ caffeine/l only during a transient co-culture period for 5 or $30 \mathrm{~min}$ significantly reduced the mean number of sperm cells that penetrated into the oocyte. Transient exposure of spermatozoa to caffeine for only $5 \mathrm{~min}$ increased the percentage of capacitated cells but not acrosome-reacted cells, as compared with a whole exposure treatment. Furthermore, preincubation of spermatozoa with $10 \mu \mathrm{mol}$ adenosine/l for $90 \mathrm{~min}$ increased both the incidence of capacitated cells and the monospermy rate and consequently decreased the number of sperm cells that penetrated into the oocyte. In conclusion, these results have demonstrated that a new transient co-incubation IVF system, in which denuded oocytes are co-cultured with spermatozoa in medium containing caffeine for 5 to $30 \mathrm{~min}$ and then continuing the culture in caffeine-free medium, will reduce the incidence of polyspermic penetration. Preincubation of fresh spermatozoa with adenosine before the transient co-incubation IVF can also improve the monospermy rate. Furthermore, asynchrony in the morphology of sperm nuclei in polyspermic oocytes was reduced by the pretreatment with adenosine and a brief exposure to caffeine.

Reproduction (2004) 128 789-800
\end{abstract}

\section{Introduction}

A high incidence of polyspermic penetration is still a major obstacle to the production of normal porcine embryos in vitro (Funahashi \& Day 1997, Day 2000, Abeydeera 2002, Coy \& Romar 2002, Funahashi 2003) and is probably due to a slow zona reaction and simultaneous sperm penetration (Sun et al. 1992, Wang et al. 1998). Some progress has been made towards overcoming this problem by efforts to increase the quality of in vitro matured oocytes and to decrease simultaneous penetration by regulating the sperm-zona pellucida binding (see Funahashi 2003 for review). Furthermore, some unique porcine in vitro fertilization (IVF) systems to allow a gradient arrival of actively motile spermatozoa to the surface of oocytes, including the 'climbing-over-the-wall' method (Funahashi \& Nagai 2000) and the 'straw IVF' method (Li et al. 2003), have also been developed and partially succeeded in improving the efficiency of normal fertilization. However, there seems to be much room for further improvement in the efficiency of porcine IVF systems, especially by reducing the simultaneous initiation of acrosome reaction which triggers a sperm race for penetration (Funahashi 2003). In a majority of porcine IVF systems (Cheng et al. 1986, Yoshida 1987, Nagai et al. 1988, Mattioli et al. 1989), spermatozoa and oocytes have 
been co-cultured in the presence of caffeine for several hours or overnight. Caffeine is generally thought of as a molecule that inhibits cyclic nucleotide phosphodiesterase, resulting in an increase in intracellular cyclic adenosine 3',5'-monophosphate (cAMP) (Casillas \& Hoskins 1970) and induction of capacitation and spontaneous acrosome reactions of boar spermatozoa (Funahashi et al. $2000 b, c)$. If caffeine is added to IVF medium, in fact, sperm penetration is achieved by $6 \mathrm{~h}$ after insemination, accompanied by an increase in polyspermic penetration (Abeydeera \& Day 1997, Shimada et al. 2000, Funahashi \& Nagai 2001). Since acrosome-intact boar spermatozoa are known to initiate binding to the porcine zona pellucida (Fazeli et al. 1997), a relatively longer duration of co-culture of gametes in the presence of caffeine may increase the chance for more spermatozoa to bind to the zona pellucida, to induce the capacitation/acrosome reaction and to achieve penetration within a narrow window. Although it was recently demonstrated that a shortened period of sperm-oocyte co-culture during IVF significantly reduced the incidence of polyspermic penetration into porcine oocytes matured in vitro (Grupen \& Nottle 2000, Gil et al. 2004), these gametes were still exposed to caffeine for more than $5 \mathrm{~h}$ after co-culture. Therefore, not only a reduced period of co-culture of gametes, such as the two-step IVF procedure (Grupen \& Nottle 2000, Gil et al. 2004), but also a short exposure of spermatozoa to caffeine may decrease the number of spermatozoa initiating penetration of the zona pellucida and consequently reduce the incidence of simultaneous multiple sperm penetration.

Furthermore, we recently demonstrated that both adenosine and fertilization-promoting peptide (FPP, which is a tripeptide, pGlu-Glu-ProNH ${ }_{2}$ ) induce capacitation of both fresh and frozen-thawed boar spermatozoa in vitro but prevent a spontaneous acrosome reaction via the adenylyl cyclase/cAMP pathway, even in the presence of caffeine (Funahashi et al. 2000b,c). Supplementation with adenosine and FPP during co-culture of oocytes with frozen-thawed spermatozoa increased the proportion of monospermic penetration (Funahashi et al. 2000c). Although utilization of adenosine or FPP in combination with the current transient co-culture IVF system may be expected to reduce the polyspermic penetration rate further, the efficacy of adenosine or FPP to achieve a successful incidence of monospermic penetration in an IVF system with fresh boar spermatozoa has not been demonstrated.

In the present study, to enhance the concept of a brief gamete co-culture system (Grupen \& Nottle 2000, Gil et al. 2004), the effect of a transient exposure of fresh boar spermatozoa to caffeine on the incidence of monospermic penetration into porcine oocytes was examined. The effect of preincubation of fresh spermatozoa with adenosine on monospermic penetration was also examined in the current transient exposure system.

\section{Materials and Methods \\ Chemicals and culture media}

$\mathrm{KCl}, \mathrm{KH}_{2} \mathrm{PO}_{4}, \mathrm{MgCl}_{2}, \mathrm{CaCl}_{2}$, sodium citrate and citric acid were purchased from Ishizu Pharmaceutical Co. Ltd (Osaka, Japan). $\mathrm{NaCl}$ and paraffin liquid were obtained from Nacalai Tesque Inc. (Kyoto, Japan). Other chemicals were purchased from Sigma Aldrich Japan K K (Tokyo, Japan). As a caffeine reagent, a mixture of caffeine and sodium benzoate at equal weight (C-4144; Sigma) was used in this study.

The medium used for the collection of oocyte-cumulus complexes and washing was modified TL-HEPES-PVA medium composed of $114 \mathrm{mmol} \mathrm{NaCl} / \mathrm{l}, 3.2 \mathrm{mmol} \mathrm{KCl} / \mathrm{l}$, $2 \mathrm{mmol} \mathrm{NaHCO}_{3} / \mathrm{l}, 0.34 \mathrm{mmol} \mathrm{KH}_{2} \mathrm{PO}_{4} / \mathrm{l}, 10 \mathrm{mmol} \mathrm{Na}-$ lactate $/ \mathrm{l}, \quad 0.5 \mathrm{mmol} \mathrm{MgCl}_{2} / \mathrm{l}, 2 \mathrm{mmol} \mathrm{CaCl}_{2} / \mathrm{l}, 10 \mathrm{mmol}$ HEPES/l, $0.2 \mathrm{mmol}$ Na-pyruvate/l, $12 \mathrm{mmol}$ sorbitol/l, $0.1 \%(\mathrm{w} / \mathrm{v})$ polyvinylalcohol, $25 \mu \mathrm{g}$ gentamicin $/ \mathrm{ml}$ and $65 \mu \mathrm{g}$ potassium penicillin $\mathrm{G} / \mathrm{ml}$. The basic maturation medium (OMM37) used was bovine serum albumin (BSA)free North Carolina State University 37 (NCSU-37) medium (Petters \& Wells 1993) supplemented with $0.6 \mathrm{mmol}$ cysteine $/ \mathrm{l}, 5 \mu \mathrm{g}$ insulin $/ \mathrm{ml}$ and $10 \%(\mathrm{v} / \mathrm{v})$ porcine follicular fluid (Funahashi et al. 1997). The basic medium for fertilization in vitro was modified Medium 199 (m-M199), which is Medium 199 with Earle's salts (GIBCO; Invitrogen Corp., Carlsbad, CA, USA) supplemented with $3.05 \mathrm{mmol}$ glucose/l, $2.92 \mathrm{mmol}$ hemi-calcium lactate/l, $0.91 \mathrm{mmol}$ sodium pyruvate/l, $1200 \mathrm{mmol}$ sorbitol/l, $25 \mu \mathrm{g}$ gentamicin $/ \mathrm{ml}, 65 \mu \mathrm{g}$ potassium penicillin $\mathrm{G} / \mathrm{ml}$ and $0.4 \%(\mathrm{w} / \mathrm{v})$ BSA (Sigma). The medium used as semen diluent was the modified Modena solution prepared with $152.64 \mathrm{mmol}$ glucose $/ \mathrm{l}, \quad 23.46 \mathrm{mmol}$ sodium citrate $/ \mathrm{l}, 11.9 \mathrm{mmol}$ $\mathrm{NaHCO}_{3} / \mathrm{l}, 6.99 \mathrm{mmol}$ EDTA-2Na/l, $46.66 \mathrm{mmol}$ Tris/l, $15.10 \mathrm{mmol}$ citric acid/l and $10 \mathrm{mg}$ gentamicin sulfate/l. All media without modified TL-HEPES-PVA and modified Modena solution were equilibrated under paraffin liquid at $39^{\circ} \mathrm{C}$ in an atmosphere of $5 \% \mathrm{CO}_{2}$ in air overnight prior to incubation with oocytes. Porcine follicular fluid was prepared from antral follicles $(3-6 \mathrm{~mm}$ in diameter) as described previously (Funahashi et al. 1994).

\section{Preparation and culture of cumulus-oocyte complexes}

Ovaries were collected from slaughtered prepubertal gilts at a local abattoir and transported to the laboratory within $2 \mathrm{~h}$ at $28-33^{\circ} \mathrm{C}$. Cumulus-oocyte complexes were aspirated through an 18 gauge needle into a disposable $10 \mathrm{ml}$ syringe from antral follicles $(3-6 \mathrm{~mm}$ in diameter) on the surface of ovaries, washed three times with modified TL-HEPES-PVA medium, and then collected in fresh modified TL-HEPES-PVA medium at room temperature (Wongsrikeao et al. 2004). This process was completed within $90 \mathrm{~min}$. Oocytes were matured in an in vitro maturation (IVM) system that has been reported to produce blastocysts and piglets efficiently following IVF and embryo 
transfer (Funahashi et al. 1997). Briefly, 50 cumulusoocyte complexes with uniform ooplasm and a compact cumulus cell mass were washed three times with OMM37 supplemented with $1 \mathrm{mmol}$ dibutyryl cAMP/l, $10 \mathrm{IU}$ eqine chorionic gonadotropin (eCG)/ml and $10 \mathrm{IU}$ human chorionic gonadotropin $(\mathrm{hCG}) / \mathrm{ml}$, and subsequently cultured in $500 \mu \mathrm{l}$ of the same medium covered with paraffin oil for $20 \mathrm{~h}$ at $39^{\circ} \mathrm{C}$ in an atmosphere of $5 \% \mathrm{CO}_{2}$ in air. The complexes were then transferred to $500 \mu \mathrm{l} \mathrm{OMM} 37$ (without dibutyryl cAMP, eCG and hCG) after washing three times with the same medium. The complexes were cultured for an additional $24 \mathrm{~h}$ (Funahashi et al. 1994). After culture, oocytes were stripped of cumulus cells by pipetting with $0.1 \%(\mathrm{w} / \mathrm{v})$ hyaluronidase and washed three times with m-M199.

\section{Preparation of fresh boar spermatozoa and ICF}

Semen-rich fractions $(30-50 \mathrm{ml})$ were collected from four Berkshire boars by the glove-hand method at a local experimental station and diluted four times with modified Modena solution. The diluted semen samples from different sperm sources in each replication were transported to the laboratory at $26-32{ }^{\circ} \mathrm{C}$ within $2 \mathrm{~h}$ after collection. After washing once by centrifugation at $750 \mathrm{~g}$ for $3 \mathrm{~min}$, spermatozoa were re-suspended at a concentration of $1 \times 10^{8}$ cells $/ \mathrm{ml}$ in modified Modena solution containing $5 \mathrm{mmol}$ cysteine/l and $20 \%(\mathrm{v} / \mathrm{v})$ boar seminal plasma. Diluted sperm suspension was cooled down from room temperature to $15^{\circ} \mathrm{C}$ for $4 \mathrm{~h}$ and then kept overnight at the same temperature. Just before use, stored spermatozoa were placed at room temperature for 15-20 min, washed three times by centrifugation at $750 \mathrm{~g}$ for $3 \mathrm{~min}$ with modified TL-HEPES-PVA solution and then re-suspended at a concentration of $5 \times 10^{5}$ cells $/ \mathrm{ml}$ in m-M199 supplemented with or without adenosine.

Just after dilution or preincubation for $90 \mathrm{~min}$ at $5 \times 10^{5}$ cells $/ \mathrm{ml}$ in m-M199 containing or not containing adenosine, $50 \mu \mathrm{l}$ diluted sperm suspension was inseminated in the same volume of m-M199 containing or not containing $10 \mathrm{mmol}$ caffeine/l. Thirty denuded oocytes were co-cultured with spermatozoa (at a final sperm concentration of $\left.2.5 \times 10^{5} \mathrm{cells} / \mathrm{ml}\right)$ in $100 \mu \mathrm{l}$ droplets of m-M199 containing $5 \mathrm{mmol}$ caffeine/l (n-M199-caffeine) under paraffin oil for 5-30 min. After co-culture, the oocytes were gently washed once with n-M199-caffeine or m-M199, transferred to a fresh $100 \mu \mathrm{l}$ droplet of the same medium without spermatozoa and the culture was continued at $39^{\circ} \mathrm{C}$ in an atmosphere of $5 \% \mathrm{CO}_{2}$ in air until $8 \mathrm{~h}$ after insemination. Since sperm penetration occurs within $6 \mathrm{~h}$ after insemination in the presence of caffeine or adenosine (Funahashi \& Nagai 2001), the cultured eggs were fixed at $8 \mathrm{~h}$ after insemination, stained with $1 \%(\mathrm{w} / \mathrm{v})$ orcein, and examined at $200 \times$ and $400 \times$ magnification. Oocytes were designated as penetrated when they had at least one sperm head, a decondensed sperm nucleus, or a male pronucleus and corresponding sperm tail in the vitellus.

\section{Chlortetracycline (CTC) fluorescence assessment of spermatozoa}

The methods used for CTC analysis were essentially those described previously (Funahashi et al. 2000b) with minor modifications. Briefly, $8 \mu \mathrm{l}$ of $100 \mu \mathrm{g}$ Hoechst bis-benzimide $33258 / \mathrm{ml}$ (Sigma) was added to $792 \mu \mathrm{l}$ sperm suspension. After gentle mixing, each suspension was incubated for $3 \mathrm{~min}$ at room temperature in the dark, then layered onto $4 \mathrm{ml}$ of $3 \%(\mathrm{w} / \mathrm{v})$ polyvinylpyrolidone (PVP40) in TL-HEPES-PVA and centrifuged at $750 \mathrm{~g}$ for $3 \mathrm{~min}$. The pelleted spermatozoa were resuspended in $45 \mu \mathrm{l} \mathrm{TL}$ HEPES-PVA and $45 \mu \mathrm{l}$ of this suspension was added to $45 \mu \mathrm{l}$ CTC solution, containing $750 \mu \mathrm{mol}$ CTC/l, $5 \mathrm{mmol}$ cysteine/l, $130 \mathrm{mmol} \mathrm{NaCl} / \mathrm{l}$ and $20 \mathrm{mmol}$ Tris/l $(\mathrm{pH} 7.8)$. Sperm cells were fixed by adding $8 \mu \mathrm{l} 12.5 \%(\mathrm{w} / \mathrm{v})$ paraformaldehyde in $0.5 \mathrm{~mol}$ Tris- $\mathrm{HCl} / \mathrm{l}(\mathrm{pH} 7.4)$. The CTC solution was prepared daily. Slides were prepared by placing $10 \mu \mathrm{l}$ of the fixed sperm suspension on a slide and one drop of $0.22 \mathrm{~mol}$ 1,4-diazabicyclo[2.2.2] octane/l dissolved in glycerol:TL-HEPES-PVA (9:1) which was then carefully mixed in order to retard fading of the fluorescence. A coverslip was added and sealed with colorless nail varnish. Spermatozoa were assessed under a phase-contrast microscope, equipped with epifluorescent optics, on the same day. Each cell was first observed under u.v. illumination (excitation at $330-380 \mathrm{~nm}$, emission at $420 \mathrm{~nm}$ ) to determine the live/dead status; the sperm cells showing bright blue staining of the nucleus were considered to be dead and were not counted. More than 100 live sperm were then examined under blue-violet illumination (excitation at $400-440 \mathrm{~nm}$, emission at $470 \mathrm{~nm}$ ) and classified according to CTC staining patterns. The three fluorescent staining patterns identified were: $F$, with uniform fluorescence over the whole sperm head; $B$, with a fluorescence-free band in the post-acrosome region; and $A R$, with almost no fluorescence over the sperm head except for a thin band of fluorescence in the equatorial segment.

\section{Experimental design}

The experimental design is schematically represented in Fig. 1.

In the first experiments, to determine if the beneficial effect of a shortened co-culture period of oocytes on the monospermic penetration rate was observed even with fresh spermatozoa, the co-culture duration was shortened from 30 to $5 \mathrm{~min}$. After co-culture with fresh spermatozoa in n-M199-caffeine for 5, 10, 15 and $30 \mathrm{~min}$ at $39^{\circ} \mathrm{C}$ in an atmosphere of $5 \% \mathrm{CO}_{2}$ in air, 30 oocytes were gently washed once with $\mathrm{n}-\mathrm{M} 199$-caffeine, transferred to a fresh $100 \mu \mathrm{l}$ droplet of the same medium without spermatozoa and the culture continued until $8 \mathrm{~h}$ after insemination.

In the second experiment, the relation between the duration of co-culture with fresh spermatozoa and the number of sperm binding to the zona pellucida was determined. At $5 \mathrm{~min}$ and $8 \mathrm{~h}$ of co-culture of gametes in 
Exp.1. Effect of co-incubation period

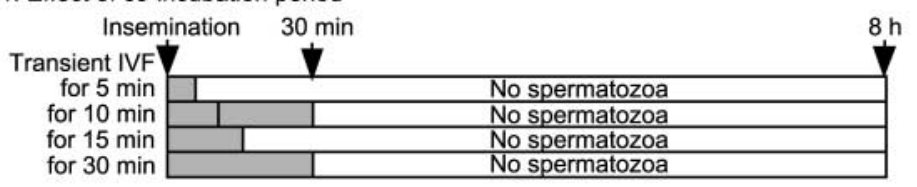

Sperm conc.: $2.5 \times 10^{5}$ cells/ml, IVF medium: m-M199 + 5 mmol caffeine/l

Exp. 2. Sperm-zona binding during co-culture

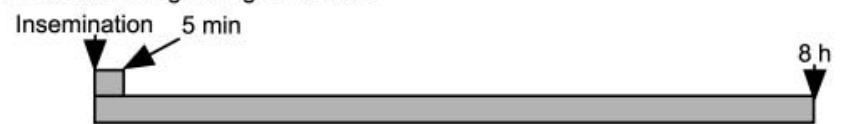

Sperm conc.: $2.5 \times 10^{5}$ cells/ml, IVF medium: m-M199 + 5 mmol caffeine/l

Exp. 3. Effect of the presence of caffeine

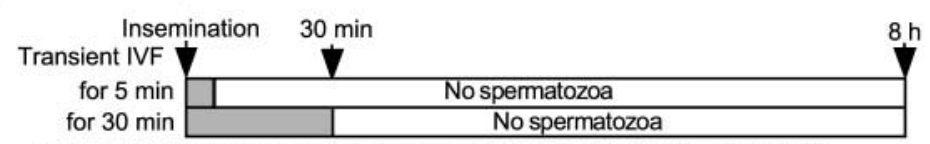

Sperm conc.: $2.5 \times 10^{5}$ cells/ml, IVF medium: m-M199 + 5 mmol caffeine/l

Exp. design: 2 co-culture periods $x 4$ groups

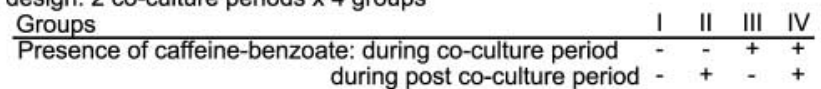

Exp. 4. СTC patterns of sperm after transient exposure to caffeine

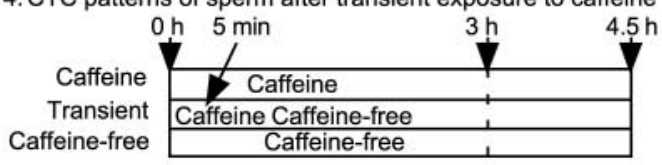

Sperm conc.: $2.5 \times 10^{5}$ cells $/ \mathrm{ml}$, medium: m-M199 + 5 mmol caffeine/l

Exp. 5. In vitro development of IVF embryos

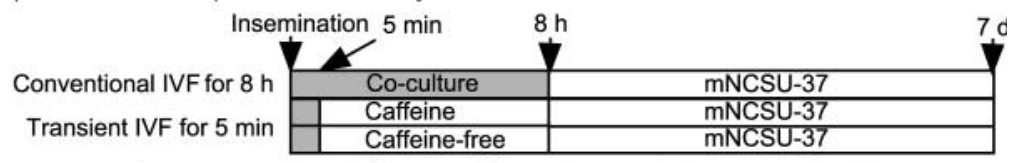

Sperm conc.: $2.5 \times 10^{5}$ cells/ml, IVF medium: m-M199 + 5 mmol caffeine/l

Exp. 6. Effect of preincubation with $10 \mathrm{~mol}$ adenosine/l

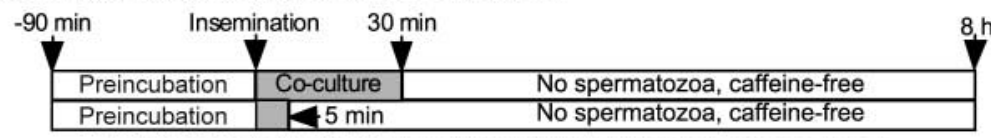

Sperm conc.: $2.5 \times 10^{5}$ cells/ml, IVF medium: m-M199 + 5 mmol caffeine/l

Exp. design: Groups

\begin{tabular}{lccccc}
\hline Co-culture period $(\mathrm{min})$ & $\mathrm{I}$ & $\mathrm{II}$ & $\mathrm{III}$ & $\mathrm{IV}$ & $\mathrm{V}$ \\
Presence of $10 \mu \mathrm{mol}$ adenosine/l during preincubation & 30 & 30 & 30 & 30 & 5 \\
Presence of $5 \mathrm{mmol}$ caffeine/l during co-culture & - & + & + & + & +
\end{tabular}

Exp. 7. CTC patterns of sperm preincubated with $10 \mu \mathrm{mol}$ adenosine/l

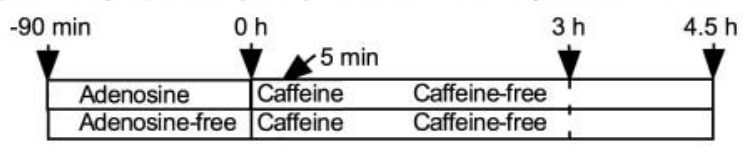

Sperm conc.: $2.5 \times 10^{5}$ cells $/ \mathrm{ml}$, Basic medium: m-M199 \pm 5 mmol caffeine/l
Figure 1 Schematic representation of experimental (Exp.) design, showing the different treatments, sperm concentrations and durations.
n-M199-caffeine at $39^{\circ} \mathrm{C}$ in an atmosphere of $5 \% \mathrm{CO}_{2}$ in air, the oocytes were washed once with TL-HEPES-PVA and fixed with $3 \%$ paraformaldehyde in TL-HEPES-PVA for $30 \mathrm{~min}$ at room temperature. According to a previous report (Katayama et al. 2002), the oocytes were processed and stained with $20 \mu \mathrm{g} / \mathrm{ml}$ lectin from Archis hypogaea (peanut) conjugated fluorescein isothiocyanate (FITC-PNA) and $400 \mu \mathrm{l} / \mathrm{ml}$ propidium iodide. The number of spermatozoa binding to the surface of zona pellucida was observed by using a confocal laser scanning microscope (MRC1024; Nippon Bio-Rad Laboratories, Tokyo, Japan). 
In the third experiment, the effect of the presence of caffeine during co-culture and the post co-culture periods was examined. After co-culture with fresh spermatozoa in $\mathrm{m}-\mathrm{M} 199$ or n-M199-caffeine for 5 or $30 \mathrm{~min}$ at $39^{\circ} \mathrm{C}$ in an atmosphere of $5 \% \mathrm{CO}_{2}$ in air, oocytes were gently washed once with sperm-free m-M199, transferred to a $100 \mu \mathrm{l}$ droplet of fresh n-M199-caffeine or m-M199 and the culture continued until $8 \mathrm{~h}$ after insemination.

In the fourth experiment, the effect of transient exposure to caffeine on sperm function was examined. Fresh spermatozoa were cultured in $\mathrm{n}-\mathrm{M} 199$-caffeine for $5 \mathrm{~min}$ at $39^{\circ} \mathrm{C}$ in an atmosphere of $5 \% \mathrm{CO}_{2}$ in air, and then culture continued in m-M199 after washing by centrifugation twice at $750 \mathrm{~g}$ for $3 \mathrm{~min}$. At 3 and $4.5 \mathrm{~h}$ after the start of culture, CTC patterns of the sperm cells were compared with those of spermatozoa cultured in m-M199 or n-M199-caffeine for the whole duration of 3 or $4.5 \mathrm{~h}$.

In the fifth experiment, in vitro development of oocytes fertilized in a transient IVF system was compared with that of oocytes fertilized in a conventional IVF system. After transient co-culture with spermatozoa at a concentration of $2.5 \times 10^{5}$ cells $/ \mathrm{ml}$ in $\mathrm{n}-\mathrm{M} 199$-caffeine for $5 \mathrm{~min}$ at $39^{\circ} \mathrm{C}$ in an atmosphere of $5 \% \mathrm{CO}_{2}$ in air and gentle washing, the oocytes were transferred to m-M199 or $\mathrm{n}-\mathrm{M199}$-caffeine. At $8 \mathrm{~h}$ after insemination, the oocytes in transient and conventional IVF systems were moved again to modified NCSU-37 medium supplemented with $0.4 \%$ $(\mathrm{w} / \mathrm{v}) \mathrm{BSA}, 0.6 \mathrm{mmol}$ cysteine/l and $5 \mu \mathrm{g}$ insulin $/ \mathrm{ml}$ and cultured for 7 days.

In the sixth experiment, the effect of preincubation of spermatozoa with adenosine before insemination was determined by using the transient co-incubation IVF system which was developed in the third experiment. Before insemination, spermatozoa were preincubated at a concentration of $5 \times 10^{5}$ cell $\mathrm{s} / \mathrm{ml}$ in the absence or presence of $10 \mu \mathrm{mol}$ adenosine $/ \mathrm{l}$ in $\mathrm{m}-\mathrm{M} 199$ in an atmosphere of $5 \% \mathrm{CO}_{2}$ in air at $39^{\circ} \mathrm{C}$ for $90 \mathrm{~min}$. After co-culture with the spermatozoa (at a final concentration of $2.5 \times 10^{5}$ cells/ml) in m-M199 or n-M199-caffeine for 5 or $30 \mathrm{~min}$, oocytes were gently washed once with sperm-free m-M199, transferred to a $100 \mu \mathrm{l}$ droplet of fresh m-M199 and the culture continued until $8 \mathrm{~h}$ after insemination.

In the final (seventh) experiment, the effect of preincubation with adenosine on sperm function was determined. Fresh spermatozoa at a concentration of $5 \times 10^{5}$ cells $/ \mathrm{ml}$ were precultured in m-M199 supplemented with or without $10 \mu \mathrm{mol}$ adenosine $/ \mathrm{l}$ for $90 \mathrm{~min}$ and then cultured in n-M199-caffeine for $5 \mathrm{~min}$ (at a concentration of $2.5 \times 10^{5}$ cell $\mathrm{s} / \mathrm{ml}$ ). After washing by centrifugation twice at $750 \mathrm{~g}$ for $3 \mathrm{~min}$, the sperm cell culture was continued in m-M199 at $2.5 \times 10^{5} \mathrm{cell} / \mathrm{s} / \mathrm{ml}$. At 3 and $4.5 \mathrm{~h}$ after exposure to caffeine, the CTC patterns of the sperm cells were examined.

\section{Statistical analysis}

Statistical analyses of results from four to six replicate experiments were used for treatment comparisons and carried out by one-way or two-way ANOVA using the JMP 5.0 (SAS Institute, Inc., Cary, NC, USA) program. If the $P$ value was smaller than 0.05 in ANOVA, Tukey-Kramer's HSD test was followed using the same program. All percentage data were subjected to arc-sine transformation before statistical analysis. For showing percentage data in tables and figures, those data were transformed back to the original percentages. All data are expressed as means \pm S.E.M. $P<0.05$ was considered to be statistically significant.

\section{Results}

In the present study, we did not observe any differences in penetration rates, survival rates and CTC patterns among replicated trials (ejaculates) and also among boars used $(P>0.05)$.

\section{Effect of further reduction of co-incubation period (experiment 1)}

By reducing the period of co-culture with fresh spermatozoa $\left(2.5 \times 10^{4}\right.$ cells $/ 100 \mu l$ droplet $)$ from 30 to $5 \mathrm{~min}$, the incidence of monospermic penetration in the mature oocytes examined increased from $1.9 \pm 1.2$ to $26.5 \pm 3.8 \%$, and the mean number of penetrated sperm cells per oocyte decreased from $9.6 \pm 1.0$ to $2.7 \pm 0.2$, without any reduction in the penetration rate (Table 1 ). Interestingly, the percentage of polyspermic oocytes having condensed or decondensed sperm head(s) and at least one male pronucleus was higher in the longer coculture duration (Table $1 ; 51.9 \pm 0.7 \%$ for $5 \mathrm{~min}$ and $91.2 \pm 4.2 \%$ for $30 \mathrm{~min})$.

\section{Effect of reduced co-incubation period on the number of spermatozoa binding to the zona pellucida (experiment 2)}

As shown in Fig. 2, the mean number of spermatozoa binding to the surface of zona pellucida was lower after co-culture of gametes (30 oocytes in $100 \mu \mathrm{l} \mathrm{n-M199-caf-}$ feine resuspended spermatozoa at $2.5 \times 10^{5} \mathrm{sperm} / \mathrm{ml}$ ) for $5 \mathrm{~min}$ than for $8 \mathrm{~h}$.

\section{Effect of the presence of caffeine during co-incubation (experiment 3)}

Gametes were co-incubated in m-M199 or n-M199-caffeine $(5 \mathrm{mmol} / \mathrm{l})$ for 5 or $30 \mathrm{~min}$ and then an additional culture in m-M199 or n-M199-caffeine until $8 \mathrm{~h}$ after insemination. The presence of caffeine during the transient co-culture period improved both the rates of sperm penetration and monospermic penetration in total mature oocytes examined, but did not affect the mean number of penetrated sperm cells per zygote (Table 2). Caffeine during the post co-culture period also increased both the incidence of sperm penetration and the number of penetrated sperm cells per zygote. A longer co-culture period 
Table 1 Effect of the duration of co-incubation on sperm penetration of in vitro-matured porcine oocytes at $8 \mathrm{~h}$ after insemination ${ }^{\mathrm{a}}$.

\begin{tabular}{|c|c|c|c|c|}
\hline & \multicolumn{4}{|c|}{ Co-culture period (min) } \\
\hline & 5 & 10 & 15 & 30 \\
\hline No. of oocytes examined & 116 & 103 & 136 & 160 \\
\hline No. $(\%)$ of mature oocytes & $114(98.7 \pm 0.8)$ & $103(100)$ & $135(99.4 \pm 0.6)$ & $159(99.5 \pm 0.5)$ \\
\hline Penetrated $(\%)^{\text {bc }}$ & $91.9 \pm 4.7$ & $95.8 \pm 1.6$ & $99.3 \pm 0.7$ & 100 \\
\hline MPN formed $(\%)^{\text {bd }}$ & $98.0 \pm 1.2$ & 100 & $99.0 \pm 1.0$ & 100 \\
\hline With sperm head $(\%)^{\text {be }}$ & $51.9 \pm 0.7^{f}$ & $67.7 \pm 0.1^{\mathrm{fg}}$ & $76.4 \pm 6.0^{\mathrm{gh}}$ & $91.2 \pm 4.2^{\mathrm{h}}$ \\
\hline Monospermy $(\%)^{b c}$ & $26.5 \pm 3.8^{f}$ & $10.2 \pm 2.3^{\mathrm{g}}$ & $4.0 \pm 1.2^{\mathrm{h}}$ & $1.9 \pm 1.2^{\mathrm{h}}$ \\
\hline Sperm/penetrated egg ${ }^{\mathrm{b}}$ & $2.7 \pm 0.2^{f}$ & $3.9 \pm 0.2^{\mathrm{fg}}$ & $5.0 \pm 0.7^{g}$ & $9.6 \pm 1.0^{\mathrm{h}}$ \\
\hline
\end{tabular}

${ }^{a}$ After co-culture with spermatozoa, oocytes were washed once and transferred to fresh media containing 5 mmol caffeine/l but without sperm cells. The culture was continued until $8 \mathrm{~h}$ after insemination.

${ }^{b}$ Data are given as means \pm S.E.M. from four and five replicated experiments.

${ }^{\mathrm{c}}$ Percentage of oocytes matured.

${ }^{\mathrm{d}}$ Percentage of oocytes penetrated.

e Percentage of oocytes that formed at least one male pronucleus (MPN). Condensed and decondensed sperm head are contained.

${ }^{\mathrm{f}-\mathrm{h}}$ Values with different superscripts within rows are significantly different $(P<0.05)$.

of $30 \mathrm{~min}$, as compared with $5 \mathrm{~min}$ duration, did not decrease either the incidence of total sperm penetration or monospermic penetration but increased the mean number of spermatozoa that penetrated into an oocyte.

Furthermore, even if oocytes were co-cultured in the absence of caffeine for 5 or $30 \mathrm{~min}$ and then cultured in sperm-free $\mathrm{n}$-M199-caffeine until $8 \mathrm{~h}$ after insemination, the rates of sperm penetration and monospermic penetration or the mean number of spermatozoa in a penetrated oocyte were similar to those of oocytes exposed to caffeine during both co-culture and the rest culture (post co-culture) period (Table 2). If gametes were not exposed to caffeine during both co-culture and the rest culture duration, penetration rate was very low $(3.3 \pm 2.7$ and $5.1 \pm 2.6 \%$ in oocytes co-cultured with spermatozoa for 5 and $30 \mathrm{~min}$ respectively). The incidence of oocytes containing both condensed or decondensed sperm head(s)

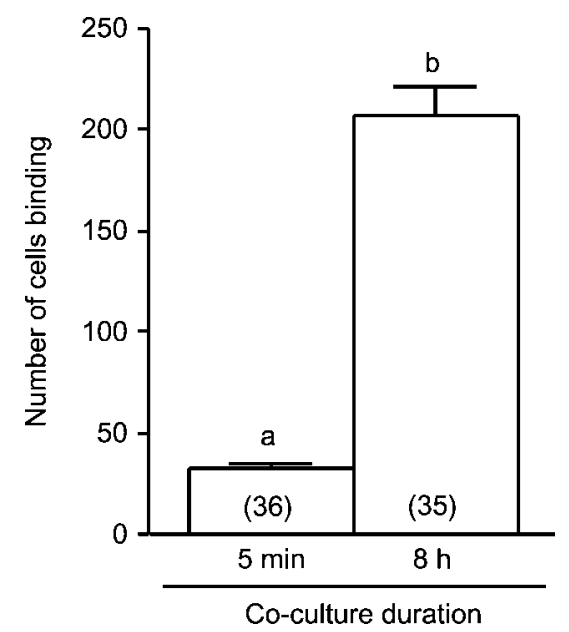

Figure 2 Number (means \pm S.E.M.) of spermatozoa binding to the surface of zona pellucida after denuded oocytes were co-cultured with spermatozoa $\left(2.5 \times 10^{5}\right.$ cells $\left./ \mathrm{ml}\right)$ for $5 \mathrm{~min}$ or $8 \mathrm{~h}$. Numbers in parentheses indicate the number of oocytes examined in three replicate experiments. Different letters above the bars indicate significant differences $(P<0.05)$. and at least one male pronucleus was lower when the oocytes were co-cultured for a brief period and then followed by culture in the absence of caffeine (Table 2).

\section{CTC patterns of spermatozoa after transient exposure to caffeine (experiment 4)}

As shown in Fig. 3, survival rate and CTC patterns were affected by both culture periods and treatments. Even transient exposure of spermatozoa to $5 \mathrm{mmol}$ caffeine/l for 5 min reduced the incidence of intact $F$ pattern cells and increased the capacitated B pattern and acrosome-reacted AR pattern cells during culture for $4.5 \mathrm{~h}$ as compared with negative controls (not exposed to caffeine). However, the incidence of capacitated $\mathrm{F}$ pattern cells was not different from positive controls (exposed to caffeine for the whole duration) but the incidence of acrosome-reacted AR pattern cells was lower.

\section{In vitro development of oocytes fertilized in conventional or transient IVF systems (experiment 5)}

As shown in Fig. 4, the percentages of cleavage and blastocyst formation were not different among treatment groups.

\section{Effect of preincubation of spermatozoa with adenosine (experiment 6)}

As shown in Table 3, regardless of the presence of $10 \mu \mathrm{mol}$ adenosine/l during preincubation of spermatozoa for $90 \mathrm{~min}$, the percentage of penetrated oocytes was increased when denuded oocytes were co-cultured with spermatozoa in the presence of caffeine. Regardless of the presence of $5 \mathrm{mmol}$ caffeine/l, however, the incidence of monospermic penetration in mature oocytes examined $8 \mathrm{~h}$ after insemination was significantly improved when spermatozoa were preincubated in the presence of $10 \mu \mathrm{mol}$ adenosine/l for $90 \mathrm{~min}$ following co-incubation with denuded oocytes. The mean number of sperm cells penetrated into an oocyte was decreased by adenosine during 
Table 2 Effect of the presence of $5 \mathrm{mmol}$ caffeine-benzoate/l during co-incubation and the rest culture until $8 \mathrm{~h}$ after insemination on sperm penetration of in vitro-matured porcine oocytes.

\begin{tabular}{|c|c|c|c|c|c|c|c|c|c|c|c|}
\hline \multirow{4}{*}{$\begin{array}{l}\text { Co-culture duration (min) } \\
\text { Concentration of caffeine } \\
\text { During co-culture } \\
\text { During the rest culture }\end{array}$} & \multicolumn{8}{|c|}{ Treatments $^{\mathrm{a}}$} & \multicolumn{3}{|c|}{ Significance of effects ( $P$ value) } \\
\hline & 5 & 5 & 5 & 5 & 30 & 30 & 30 & 30 & & Caffeine & $\begin{array}{l}\text { Caffeine } \\
\text { during }\end{array}$ \\
\hline & $0 \mathrm{mmol} / \mathrm{l}$ & $0 \mathrm{mmol} / \mathrm{l}$ & $5 \mathrm{mmol} / \mathrm{l}$ & $5 \mathrm{mmol} / \mathrm{l}$ & $0 \mathrm{mmol} / \mathrm{l}$ & $0 \mathrm{mmol} / \mathrm{l}$ & $5 \mathrm{mmol} / \mathrm{l}$ & $5 \mathrm{mmol} / \mathrm{l}$ & Co-culture & during & the rest \\
\hline & $0 \mathrm{mmol} / \mathrm{l}$ & $5 \mathrm{mmol} / \mathrm{l}$ & $0 \mathrm{mmol} / \mathrm{l}$ & $5 \mathrm{mmol} / \mathrm{l}$ & $0 \mathrm{mmol} / \mathrm{l}$ & $5 \mathrm{mmol} / \mathrm{l}$ & $0 \mathrm{mmol} / \mathrm{l}$ & $5 \mathrm{mmol} / \mathrm{l}$ & duration & co-culture & culture \\
\hline No. of oocytes examined & 156 & 156 & 157 & 141 & 167 & 153 & 148 & 158 & & & \\
\hline No. $(\%)$ of mature eggs & 142 & 153 & 148 & 140 & 151 & 151 & 144 & 157 & & & \\
\hline & $(91.3 \pm 1.1)$ & $(98.0 \pm 0.8)$ & $(94.1 \pm 2.1)$ & $(99.5 \pm 0.5)$ & $(90.7 \pm 2.1)$ & $(98.7 \pm 0.8)$ & $(97.3 \pm 0.7)$ & $(99.5 \pm 0.5)$ & 0.527 & 0.031 & $<0.001$ \\
\hline Penetrated $(\%)^{\mathrm{bc}}$ & $3.3 \pm 2.7$ & $95.3 \pm 1.9$ & $84.6 \pm 6.9$ & $96.8 \pm 3.2$ & $5.1 \pm 2.6$ & $96.9 \pm 1.9$ & $87.9 \pm 5.4$ & $99.5 \pm 0.5$ & 0.277 & $<0.001$ & $<0.001$ \\
\hline MPN formed $(\%)^{\text {bd }}$ & $75.0 \pm 25.0$ & $99.2 \pm 0.8$ & $95.4 \pm 3.2$ & $98.4 \pm 1.0$ & 100 & $99.2 \pm 0.8$ & $87.1 \pm 6.0$ & 100 & 0.167 & 0.571 & 0.005 \\
\hline With sperm head $(\%)^{\text {be }}$ & $25.0 \pm 25.0$ & $51.7 \pm 1.6$ & $23.3 \pm 3.1$ & $59.3 \pm 4.8$ & $11.1 \pm 11.1$ & $76.1 \pm 8.7$ & $25.0 \pm 3.8$ & $86.8 \pm 5.7$ & 0.237 & 0.966 & $<0.001$ \\
\hline Monospermy $(\%)^{\mathrm{bc}}$ & $3.3 \pm 2.7$ & $24.6 \pm 5.8$ & $38.0 \pm 4.8$ & $25.4 \pm 5.1$ & $4.4 \pm 2.3$ & $10.7 \pm 5.6$ & $40.6 \pm 5.6$ & $3.1 \pm 1.3$ & 0.064 & $<0.001$ & 0.106 \\
\hline Sperm/penetrated egg ${ }^{b}$ & 1.0 & $2.8 \pm 0.2$ & $1.7 \pm 0.1$ & $3.4 \pm 0.4$ & $1.1 \pm 0.1$ & $5.0 \pm 1.4$ & $2.0 \pm 0.3$ & $6.9 \pm 1.4$ & 0.022 & 0.108 & $<0.001$ \\
\hline
\end{tabular}

${ }^{a}$ Oocytes were co-cultured with spermatozoa in the absence or presence of $5 \mathrm{mmol}$ caffeine-benzoate/l for 5 or 30 min, transferred to fresh $\mathrm{m}-\mathrm{M} 199 \mathrm{containing}$ or not containing $5 \mathrm{mmol}$ caffeine-benzoate/l and then cultured until $8 \mathrm{~h}$ after insemination.

${ }^{\mathrm{b}}$ Data are given as means \pm S.E.M. from five replicated experiments.

c Percentage of oocytes matured.

${ }^{d}$ Percentage of oocytes penetrated.

${ }^{\text {e }}$ Percentage of oocytes that formed at least one male pronucleus (MPN). Condensed and decondensed sperm head are contained. 

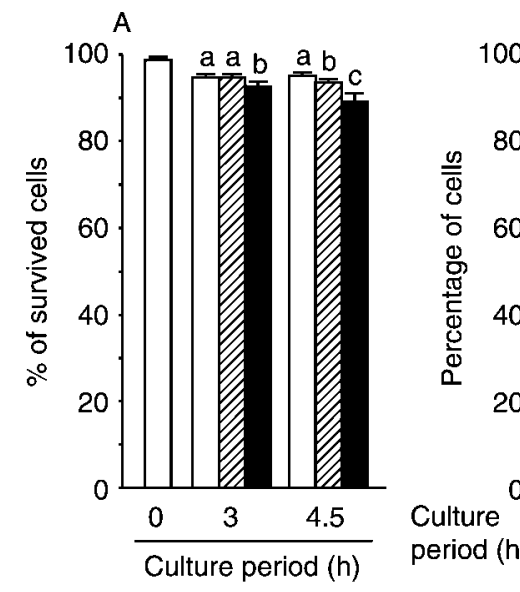

$B$

Culture
period $(h)$

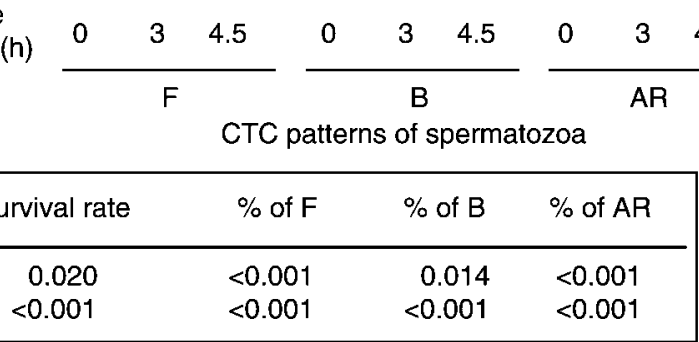

Figure 3 Effect of transient exposure to $5 \mathrm{mmol}$ caffeine/l for 5 min on CTC patterns of boar spermatozoa. At 3 and $4.5 \mathrm{~h}$ after the start of culture, survival rate (A) and CTC patterns (B) of the spermatozoa (hatched bars) were compared with those of cells exposed (solid bars) or not exposed to caffeine for the whole period (open bars). Different letters above the bars indicate significant differences within the same observation period $(P<0.05)$. preincubation and increased by caffeine during co-culture. Even if spermatozoa were preincubated in the presence of adenosine for $90 \mathrm{~min}$, the duration of the co-culture period of 5 and $30 \mathrm{~min}$ did not affect the penetration rate, incidence of monospermy and mean number of spermatozoa in penetrated oocyte. In this experiment, the incidence of oocytes containing both condensed or decondensed sperm head(s) and at least one male pronucleus was reduced by the presence of adenosine during preincubation (Table 3).

\section{CTC patterns of spermatozoa preincubated with adenosine (experiment 7 )}

When spermatozoa were preincubated in the absence or presence of $10 \mu \mathrm{mol}$ adenosine/l for $90 \mathrm{~min}$ before transient exposure to $5 \mathrm{mmol}$ caffeine/l for $5 \mathrm{~min}$, both survival rate and CTC patterns were affected by treatment and culture period after the treatment (Fig. 5). The presence of adenosine during preincubation increased the incidence of capacitated B pattern cells and decreased the incidence of acrosome-reacted AR pattern cells even 3 and $4.5 \mathrm{~h}$ after transient exposure to caffeine for $5 \mathrm{~min}$.

\section{Discussion}

In the present study, we used fresh spermatozoa because cryopreserved boar spermatozoa have been observed to show a capacitation-like reaction (Watson 1995, Green \& Watson 2001) and some damage in acrosome and flagella regions (Courtens \& Paquignon 1985).

The incidence of polyspermic fertilization in penetrated oocytes has been demonstrated to strongly correlate with the penetration rate (Marchal et al. 2002), meaning that there is a possibility that a significant reduction in the polyspermy rate does not always mean an increased number of mature oocytes penetrated by a single sperm cell. In the present study, therefore, to compare the effect of various treatments on monospermic penetration directly, the incidence is shown as a percentage of total mature oocytes examined. Furthermore, we have shown the percentage of oocytes having both at least one male pronucleus and condensed or decondensed sperm head(s).

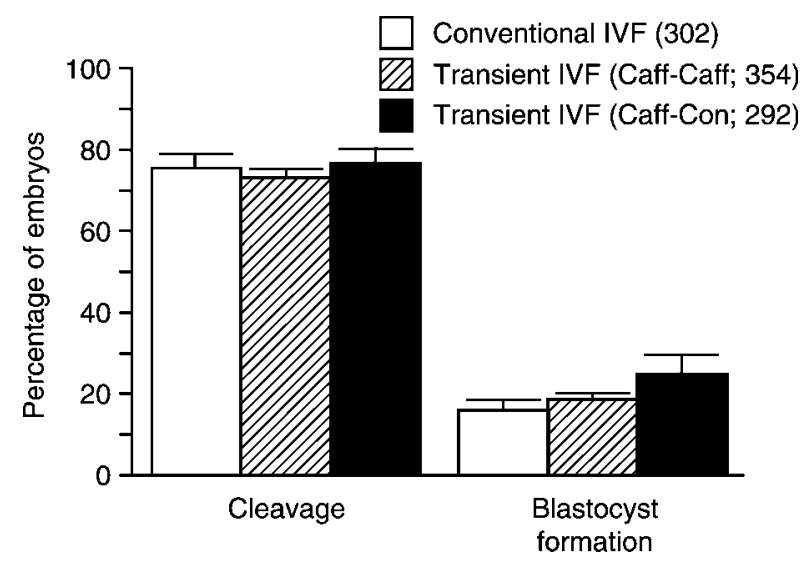

Figure 4 In vitro development of oocytes fertilized in a transient IVF system. After transient co-incubation with spermatozoa $\left(2.5 \times 10^{5}\right.$ cell $\mathrm{s} / \mathrm{ml}$ ) for $5 \mathrm{~min}$, the oocytes were transferred to $\mathrm{m}-\mathrm{M} 199$ with (Caff-Caff; hatched bars) or without $5 \mathrm{mmol}$ caffeine/l (Caff-Con; solid bars) and cultured for $8 \mathrm{~h}$. The oocytes were then transferred again to modified NCSU-37 and cultured for 7 days. As a control, oocytes were co-cultured with spermatozoa $\left(2.5 \times 10^{5} \mathrm{cell} / \mathrm{s} / \mathrm{ml}\right)$ in a conventional IVF system (m-M199 with 5 mmol caffeine/l) for $8 \mathrm{~h}$ (open bars), then transferred to modified NCSU-37 and cultured for 7 days. No significant differences were observed on cleavage or blastocyst formation. Numbers in parentheses indicate the number of oocytes examined in five replicated experiments. 
Table 3 Effect of preincubation of spermatozoa with $10 \mu \mathrm{mol}$ adenosine/l for $90 \mathrm{~min}$ before insemination on sperm penetration of in vitromatured porcine oocytes in a transient co-culture IVF system.

\begin{tabular}{|c|c|c|c|c|c|c|c|c|}
\hline \multirow{4}{*}{$\begin{array}{l}\text { Co-culture duration (min) } \\
\text { Presence of adenosine during } \\
\text { preincubation } \\
\text { Presence of caffeine during } \\
\text { co-culture }\end{array}$} & \multicolumn{5}{|c|}{ Treatments $^{\mathrm{a}}$} & \multicolumn{3}{|c|}{ Significance of effects ( $P$ value) } \\
\hline & 30 & 30 & 30 & 30 & 5 & \multirow{3}{*}{$\begin{array}{l}\text { Duration } \\
\text { of } \\
\text { co-culture }\end{array}$} & \multirow{3}{*}{$\begin{array}{l}\text { Adenosine } \\
\text { during } \\
\text { preincubation }\end{array}$} & \multirow{3}{*}{$\begin{array}{l}\text { Caffeine } \\
\text { during } \\
\text { co-culture }\end{array}$} \\
\hline & $0 \mu \mathrm{mol} / \mathrm{l}$ & $0 \mu \mathrm{mol} / \mathrm{l}$ & $10 \mu \mathrm{mol} / \mathrm{l}$ & $10 \mu \mathrm{mol} / \mathrm{l}$ & $10 \mu \mathrm{mol} / \mathrm{l}$ & & & \\
\hline & $0 \mathrm{mmol} / \mathrm{l}$ & $5 \mathrm{mmol} / \mathrm{l}$ & $0 \mathrm{mmol} / \mathrm{l}$ & $5 \mathrm{mmol} / \mathrm{l}$ & $5 \mathrm{mmol} / \mathrm{l}$ & & & \\
\hline No. of occytes examined & 164 & 151 & 156 & 165 & 164 & & & \\
\hline \multirow[t]{2}{*}{ No. $(\%)$ of mature eggs } & 145 & 147 & 144 & 151 & 155 & & & \\
\hline & $(89.8 \pm 1.6)$ & $(97.7 \pm 1.4)$ & $(92.4 \pm 1.5)$ & $(91.5 \pm 1.4)$ & $(94.5 \pm 1.5)$ & 0.472 & 0.542 & 0.040 \\
\hline Penetrated $(\%)^{b c}$ & $34.1 \pm 6.8$ & $88.6 \pm 5.9$ & $52.6 \pm 3.6$ & $81.1 \pm 2.3$ & $82.6 \pm 2.1$ & 0.376 & 0.552 & $<0.001$ \\
\hline MPN formed ${ }^{\text {bd }}$ & $91.1 \pm 4.1$ & $96.5 \pm 1.8$ & $88.3 \pm 3.2$ & $93.6 \pm 1.8$ & $95.9 \pm 1.5$ & 0.318 & 0.601 & 0.029 \\
\hline With sperm head (\%) & $31.8 \pm 4.9$ & $50.4 \pm 12.1$ & $23.8 \pm 1.1$ & $24.5 \pm 3.9$ & $25.7 \pm 9.6$ & 0.493 & 0.022 & 0.404 \\
\hline Monospermy $(\%)^{\mathrm{bc}}$ & $29.0 \pm 4.3$ & $23.6 \pm 5.5$ & $42.9 \pm 4.1$ & $47.8 \pm 3.7$ & $48.5 \pm 1.5$ & 0.092 & $<0.001$ & 0.821 \\
\hline Sperm/penetrated egg & $1.2 \pm 0.1$ & $3.1 \pm 0.8$ & $1.3 \pm 0.1$ & $1.5 \pm 0.1$ & $1.6 \pm 0.1$ & 0.633 & 0.008 & 0.002 \\
\hline
\end{tabular}

Since various morphological types of sperm nucleus can be observed in polyspermic oocytes, a difference in the percentage may reflect a change of the width of the window for sperm penetration.

In the current study, spermatozoa bound to the oocytes during co-culture for 5 or $30 \mathrm{~min}$ even in the absence of caffeine, because high penetration rates were obtained when the oocytes were followed by culture in the presence of caffeine (Table 2). However, the spermatozoa could not achieve penetration if the oocytes were continued to be cultured in a caffeine-free medium. Uncapacitated acrosome-intact spermatozoa can bind to the zona pellucida (Peterson et al. 1984), and zona pellucida can initiate acrosome reaction of boar spermatozoa in vitro (Berger et al. 1989, Melendrez et al. 1994). In the present result of the CTC assay, $96.7 \pm 0.5 \%$ of spermatozoa were intact (uncapacitated acrosome-intact) cells at insemination. The current results suggest that uncapacitated acrosome-intact spermatozoa bound to the zona pellucida can penetrate if the cells are stimulated by inducers for capacitation/acrosome reaction, such as caffeine.

Polyspermic penetration into porcine oocytes in vitro is more likely due to an incomplete or slow zona reaction or simultaneous sperm penetration rather than an abnormal cortical reaction (Wang et al. 1999). One strategy to overcome this abnormality or characteristic in porcine oocytes may be by trying to induce a complete and quick zona reaction in response to cortical exocytosis, and another
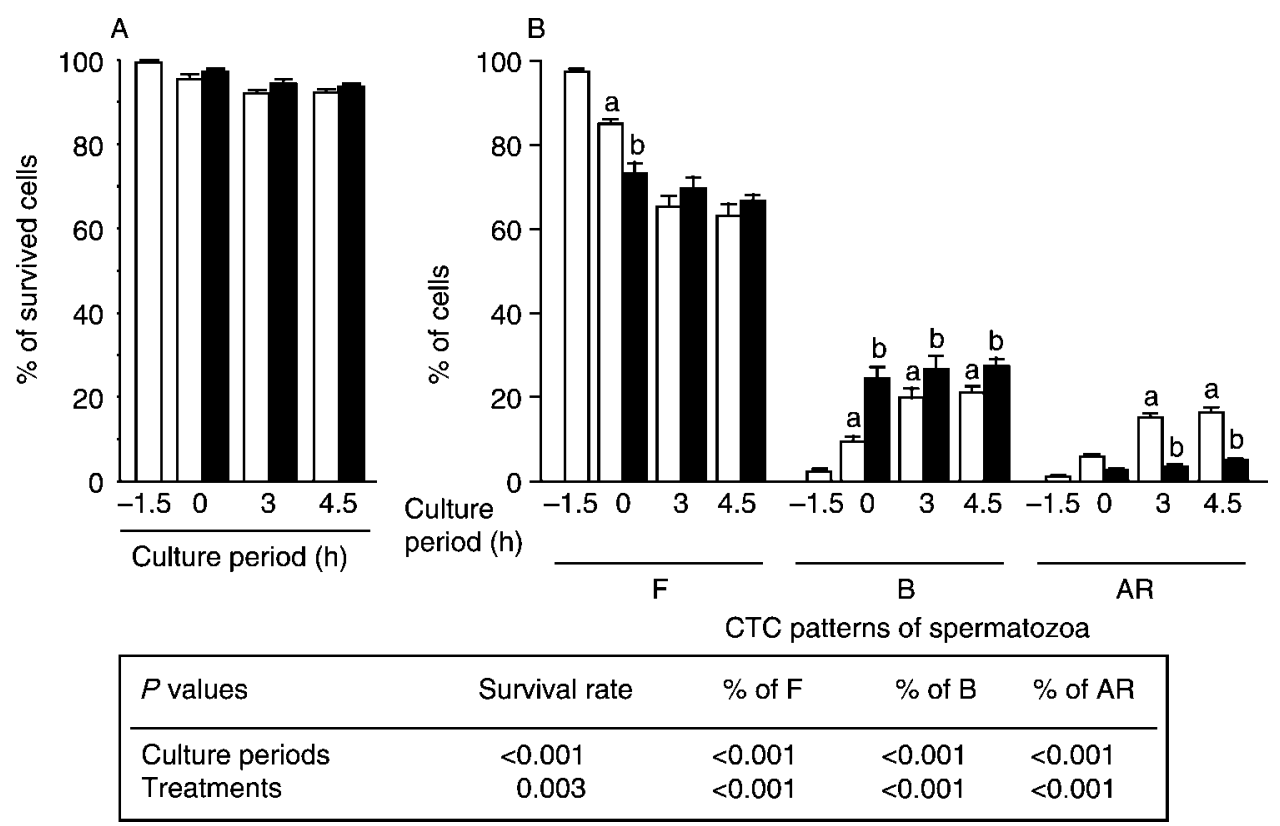

Figure 5 Effect of preincubation with $10 \mu \mathrm{mol}$ adenosine/l on CTC patterns of boar spermatozoa after transient exposure to $5 \mathrm{mmol}$ caffeine/l for $5 \mathrm{~min}$. At 3 and $4.5 \mathrm{~h}$ after the transient exposure to caffeine, survival rate (A) and CTC patterns (B) of the spermatozoa preincubated with (solid bars) or without adenosine for $90 \mathrm{~min}$ (open bars) were examined. Different letters above the bars indicate significant differences within the same observation period $(P<0.05)$. 
strategy should be to reduce the number of spermatozoa that achieve zona penetration during the relatively wide window before the zona reaction by regulating the spermzona pellucida binding. In a majority of porcine IVF systems (Cheng et al. 1986, Yoshida 1987, Nagai et al. 1988, Mattioli et al. 1989), gametes have been co-cultured in droplets of medium containing caffeine for several hours or overnight. In a conventional IVF system, both the incidence of oocytes penetrated and the percentage of polyspermy in the penetrated oocytes also appear to increase in the presence of caffeine with the duration of the co-culture and sperm concentration (Funahashi \& Nagai 2001). In the present study, we first reduced the duration of the co-incubation of oocytes with fresh spermatozoa in the presence of caffeine to confirm a concept that was demonstrated previously with frozen-thawed spermatozoa. We demonstrated here that the number of spermatozoa binding to the zona pellucida and the incidence of polyspermic penetration could be decreased by shortening the duration of co-incubation of gametes. These results were consistent with previous reports with frozen-thawed spermatozoa (Gil et al. 2004), demonstrating that shortening the co-culture duration to $10-30 \mathrm{~min}$ decreased both the number of spermatozoa bound to the zona pellucida and the incidence of polyspermy. Here we have indicated that fresh spermatozoa reduced the chance of sperm binding to the oocytes and consequently achieved a lower incidence of polyspermic penetration after shorter co-culture of gametes. However, our result showed that even fresh boar spermatozoa bound to the oocytes within $5 \mathrm{~min}$ after insemination contributed to the polyspermic fertilization in about $65 \%$ of the inseminated oocytes if an additional culture in the presence of caffeine followed. In these conditions, we also found that the incidence of IVF oocytes containing both at least one male pronucleus and condensed or decondensed sperm head(s) increased in longer co-culture periods. In the presence of caffeine even after a co-culture period, the window for sperm penetration may have become wider when a larger number of spermatozoa bound to the zona pellucida during co-culture.

In the current study, we examined the effect of caffeine during a transient co-culture and the rest culture period on sperm penetration. Caffeine has been used to induce sperm capacitation in a majority of current porcine IVF systems (Cheng et al. 1986, Yoshida 1987, Nagai et al. 1988, Mattioli et al. 1989). We have shown here that a transient exposure to $5 \mathrm{mmol}$ caffeine/l for $5 \mathrm{~min}$ is enough to induce sperm capacitation and penetration. We also demonstrated that if the oocytes were continued in culture in the absence of caffeine, the number of sperm cells penetrated within the window until the completion of the zona reaction following the first sperm penetration could be reduced because of a limited stimulation of acrosome reaction. Furthermore, the window of sperm penetration itself appears to be narrowed because the incidence of oocytes having both male pronucleus and condensed or decondensed sperm head(s) significantly decreased in this condition. If the transient co-culture was followed by an additional culture in the presence of caffeine, capacitation/acrosome reaction was stimulated and the incidence and number of spermatozoa penetrated significantly increased. These results suggest that not all spermatozoa bound to the oocytes but only a limited number of the cells seem to stimulate penetrability by caffeine during the transient co-incubation. Therefore, although there is a high correlation between the incidence of polyspermy in penetrated oocytes and the ratio of spermatozoa/oocyte penetrated in the fertilization medium (Rath 1992), we propose here that a brief period of exposure of the gametes to caffeine is also an important factor in preventing multiple penetration. The current new IVF method, a transient co-incubation in the presence of caffeine followed by culture of the oocytes in caffeine-free medium, will be useful to further increase the incidence of normal fertilization in porcine oocytes in vitro by controlling the sperm-zona binding and the penetrable window of spermatozoa.

However, a transient exposure of gametes to caffeine during a brief co-culture period did not increase the efficiency of cleavage and blastocyst formation. This result was consistent with a recent publication (Gil et al. 2004). It has also been demonstrated that polyspermic porcine IVM-IVF embryos containing multiple pronuclei can develop in vitro to the blastocyst stage at the same percentage as monospermic IVM-IVF embryos (Han et al. 1999).

It has recently been demonstrated that both adenosine and FPP can regulate the function of freshly ejaculated and frozen-thawed boar spermatozoa (Funahashi et al. $2000 b)$. Replacement of caffeine with adenosine or FPP in the fertilization medium in a conventional IVF system improved monospermic penetration by frozen-thawed boar spermatozoa (Funahashi et al. 2000c, Funahashi \& Nagai 2001). In the present study using fresh spermatozoa, we showed that preincubation of boar spermatozoa in the presence of adenosine for $90 \mathrm{~min}$ significantly increased the incidence of oocytes penetrated by a single spermatozoon and reduced the incidence of oocytes containing both male pronucleus and condensed or decondensed sperm head(s), regardless of the duration of the co-culture period within $30 \mathrm{~min}$ and of the presence of caffeine during co-incubation. These results could be due to the phenomenon that acrosome reaction of adenosine-treated cells is prevented even after a transient exposure to caffeine. These results demonstrated that a combination of preincubation of fresh spermatozoa with adenosine and a transient co-incubation IVF system is effective at narrowing the window of sperm penetration and increasing the incidence of oocytes penetrated by a single spermatozoon. Adenosine stimulates and prevents the capacitation and spontaneous acrosome reaction of boar spermatozoa respectively, via the adenylyl cyclase/cAMP pathway (Funahashi et al. 2000b). In the presence of adenosine, the timing of in vitro penetration of frozen-thawed spermatozoa appears to be slower than that in the presence of 
caffeine (Funahashi \& Nagai 2001). In this combined IVF system, therefore, a limited number of spermatozoa capacitated by preincubation with adenosine are induced in the zona-initiated acrosome reaction (Berger et al. 1989, Melendrez et al. 1994) and may penetrate the zona pellucida in a scattered manner.

In the present study, we focused only on an IVF system permitting simultaneous sperm penetration. Although treatments affecting sperm function, such as pretreatment with adenosine before transient exposure to caffeine, reduced polyspermic penetration rate and the width of the window for sperm penetration, the incidence was still unacceptable for commercial application. Ultrastructural observations of the zona pellucida of porcine oocytes (Funahashi et al. 2000a, 2001) have found morphological differences in the zona pellucida of oocytes matured in vitro and in vivo and these authors hypothesized that the differences due to a failure in final maturation may result in incomplete or delayed zona reaction. Polyspermy rate appears to be affected by the donor of oocytes (Marchal et al. 2001) and is still higher for in vitro matured oocytes than for ovulated oocytes (Wang et al. 1998). Improvement of the quality of porcine IVM oocytes and use of the oocytes in the current IVF system may help to overcome polyspermy. Furthermore, recent studies have demonstrated that exposure to porcine oviduct-specific glycoproteins before and during IVF increases the penetrability (Romar et al. 2003) and reduces the incidence of polyspermy in pig oocytes (Romar et al. 2001), and the number of bound sperm (Kouba et al. 2000, McCauley et al. 2003). Exogenous hyaluronan, which has been detected in porcine oviduct fluid (Tienthai et al. 2000), has also been demonstrated to decrease polyspermy during conventional porcine IVF (Suzuki et al. 2000). Sperm treatments before insemination (Matas et al. 2003), IVF media (Coy et al. 2002) and IVF cambers (Funahashi \& Nagai 2000, Li et al. 2003, Wheeler et al. 2004) also have been known to affect the incidence of polyspermic penetration in porcine IVF systems. Further research should be conducted into these techniques in the current transient co-incubation IVF system.

In the present study, a mixture of caffeine and sodium benzoate at equal weight was used as a caffeine reagent. Due to the presence of sodium benzoate, adding $5 \mathrm{mmol}$ caffeine/l may increase the osmolarity of the medium. Therefore, the current IVF results may contain an effect of the exposure of the gamete, not only to caffeine, but also to different osmolarities for various durations. Furthermore, since we focused on examining the effects of the duration of exposure of the gamete to caffeine, we used a concentration of caffeine at $5 \mathrm{mmol} / \mathrm{l}$ in the current study. Adjustment of the kind and concentration of caffeine should be carried out in further experiments to obtain a higher incidence of normal penetration.

In conclusion, our present study has demonstrated that a transient co-incubation of oocytes with spermatozoa in the presence of caffeine for 5 or $30 \mathrm{~min}$ followed by an additional culture in the absence of caffeine reduces the incidence of oocytes penetrated by multiple spermatozoa, suggesting that a transient duration of exposure of gametes to caffeine is an important factor in preventing polyspermic penetration into porcine oocytes. Furthermore, preincubation of spermatozoa with adenosine before a transient co-incubation narrows the window for sperm penetration and improves the incidence of monospermic fertilization, regardless of the presence of caffeine during the co-incubation period.

\section{Acknowledgements}

We thank Okayama Prefectural Center for Animal Husbandry and Research for supplying fresh boar semen. This work was supported in part by grants to $\mathrm{H} \mathrm{F}$ from the Ito Foundation and Grant-in-Aid for Scientific Research (No. 16580230) of the Japan Society for the Promotion of Science and to R R from the Ministry of Education, Culture, Sports, Science and Technology (MEXT) of Japan.

\section{References}

Abeydeera LR 2002 In vitro production of embryos in swine. Theriogenology 57 257-273.

Abeydeera LR \& Day BN 1997 Fertilization and subsequent development in vitro of pig oocytes inseminated in a modified tris-buffered medium with frozen-thawed ejaculated spermatozoa. Biology of Reproduction 57 729-734

Berger T, Turner KO, Meizel S \& Hedrick JL 1989 Zona pellucidainduced acrosome reaction in boar sperm. Biology of Reproduction 40 525-530.

Casillas ER \& Hoskins DD 1970 Activation of monkey spermatozoa adenyl cyclase by thyroxine and triiodothyronine. Biochemical and Biophysical Research Communications 40 255-262.

Cheng WTK, Polge C \& Moor RM 1986 In vitro fertilization of pig and sheep oocytes. Theriogenology 25146 (Abstract).

Courtens JL \& Paquignon M 1985 Ultrastructure of fresh, frozen, and frozen-thawed spermatozoa of the boar. Proceedings of the First International Conference on Deep Freezing of Boar Semen, pp 61-87. Eds LA Johnson \& K Larsson. Uppsala, Sweden: Swedish University of Agricultural Sciences.

Coy P \& Romar R 2002 In vitro production of pig embryos: a point of view. Reproduction, Fertility and Development 14 275-286.

Coy P, Gadea J, Romar R, Matas C \& Garcia E 2002 Effect of in vitro fertilization medium on the acrosome reaction, cortical reaction, zona pellucida hardening and in vitro development in pigs. Reproduction 124 279-288.

Day BN 2000 Reproductive biotechnologies: current status in porcine reproduction. Animal Reproduction Science 60-61 161-172.

Fazeli A, Hage WJ, Cheng FP, Voorhout WF, Marks A, Bevers MM \& Colenbrander B 1997 Acrosome-intact boar spermatozoa initiate binding to the homologous zona pellucida in vitro. Biology of Reproduction $\mathbf{5 6}$ 430-438.

Funahashi H 2003 Polyspermic penetration in porcine IVM-IVF systems. Reproduction, Fertility and Development 15 167-177.

Funahashi H \& Day BN 1997 Advances in in vitro production of pig embryos. Journal of Reproduction and Fertility Supplement $\mathbf{5 2}$ $271-283$.

Funahashi H \& Nagai T 2000 Sperm selection by a climbing-over-awall IVF method reduces the incidence of polyspermic penetration of porcine oocytes. Journal of Reproduction and Development $\mathbf{4 6}$ 319-324. 
Funahashi H \& Nagai T 2001 Regulation of in vitro penetration of frozen-thawed boar spermatozoa by caffeine and adenosine. Molecular Reproduction and Development 58 424-431.

Funahashi H, Cantley TC \& Day BN 1994 Different hormonal requirement of porcine oocyte-complexes during maturation in vitro. Journal of Reproduction and Fertility 101 159-165.

Funahashi H, Cantley TC \& Day BN 1997 Synchronization of meiosis in porcine oocytes by exposure to dibutyryl cyclic AMP improves developmental competence following in vitro fertilization. Biology of Reproduction $\mathbf{5 7} 49-53$.

Funahashi H, Ekwall H \& Rodriguez-Martinez H 2000a Zona reaction in porcine oocytes fertilized in vivo and in vitro as seen with scanning electron microscopy. Biology of Reproduction 63 1447-1452.

Funahashi H, Asano A, Fujiwara T, Nagai T, Niwa K \& Fraser LR 2000b Both fertilization promoting peptide and adenosine stimulate capacitation but inhibit spontaneous acrosome loss in ejaculated boar spermatozoa in vitro. Molecular Reproduction and Development 55 117-124.

Funahashi H, Fujiwara T \& Nagai T 2000c Modulation of the function of boar spermatozoa via adenosine and fertilization promoting peptide receptors reduce the incidence of polyspermic penetration into porcine oocytes. Biology of Reproduction 63 1157-1163.

Funahashi H, Ekwall H, Kikuchi K \& Rodriguez-Martinez H 2001 Transmission electron microscopy studies of the zona reaction in pig oocytes fertilized in vivo and in vitro. Reproduction 122 443-452.

Gil MA, Ruiz M, Vazquez JM, Roca J, Day BN \& Martinez EA 2004 Effect of short periods of sperm-oocyte coincubation during in vitro fertilization on embryo development in pigs. Theriogenology 62 544-552.

Green CE \& Watson PF 2001 Comparison of the capacitation-like state of cooled boar spermatozoa with true capacitation. Reproduction 122 889-898.

Grupen CG \& Nottle MB 2000 A simple modification of the in vitro fertilization procedure improves the efficiency of in vitro pig embryo production. Theriogenology 53422 (Abstract).

Han YM, Abeydeera LR, Kim JH, Moon HB, Cabot RA, Day BN \& Prather RS 1999 Growth retardation of inner cell mass cells in polyspermic porcine embryos produced in vitro. Biology of Reproduction 60 1110-1113.

Katayama M, Koshida M \& Miyake M 2002 Fate of the acrosome in ooplasm in pigs after IVF and ICSI. Human Reproduction 17 $2657-2664$.

Kouba AJ, Abeydeera LR, Alvarez IM, Day BN \& Buhi WC 2000 Effects of the porcine oviduct-specific glycoprotein on fertilization, polyspermy, and embryonic development in vitro. Biology of Reproduction $63242-250$.

Li YH, Ma W, Li M, Hou Y, Jiao LH \& Wang WH 2003 Reduced polyspermic penetration in porcine oocytes inseminated in a new in vitro fertilization (IVF) system: straw IVF. Biology of Reproduction 69 1580-1585.

McCauley TC, Buhi WC, Wu GM, Mao J, Caamano JN, Didion BA \& Day BN 2003 Oviduct-specific glycoprotein modulates spermzona binding and improves efficiency of porcine fertilization in vitro. Biology of Reproduction 69 828-834.

Marchal R, Feugang JM, Perreau C, Venturi E, Terqui M \& Mermillod P 2001 Meiotic and developmental competence of prepubertal and adult swine oocytes. Theriogenology 56 17-29.

Marchal R, Pelaez J, Terqui M \& Mermillod P 2002 Effect of sperm survival and CTC staining pattern on in vitro fertilization of porcine oocytes. Theriogenology 57 1917-1927.

Matas C, Coy P, Romar R, Marco M, Gadea J \& Ruiz S 2003 Effect of sperm preparation method on in vitro fertilization in pigs. Reproduction 125 133-141.

Mattioli M, Bacci ML, Galeati G \& Seren E 1989 Developmental competence of pig oocytes matured and fertilized in vitro. Theriogenology 31 1201-1207.

Melendrez CS, Meizel S \& Berger T 1994 Comparison of the ability of progesterone and heat solubilized porcine zona pellucida to initiate the porcine sperm acrosome reaction in vitro. Molecular Reproduction and Development 39 433-438.

Nagai T, Takahashi T, Masuda H, Shioya Y, Kuwayama M, Fukushima M, Iwasaki S \& Hanada A 1988 In-vitro fertilization of pig oocytes by frozen boar spermatozoa. Journal of Reproduction and Fertility 84 585-591.

Peterson RN, Russell LD \& Hunt WP 1984 Evidence for specific binding of uncapacitated boar spermatozoa to porcine zonae pellucidae in-vitro. Journal of Experimental Zoology 231 137-148.

Petters RM \& Wells KD 1993 Culture of pig embryos. Journal of Reproduction and Fertility Supplement 48 61-73.

Rath D 1992 Experiments to improve in vitro fertilization techniques for in vivo-matured porcine oocytes. Theriogenology 37 885-896.

Romar R, Coy P, Campos I, Gadea J, Matas C \& Ruiz S 2001 Effect of co-culture of porcine sperm and oocytes with porcine oviductal epithelial cells on in vitro fertilization. Animal Reproduction Science 68 85-98.

Romar R, Coy P, Ruiz S, Gadea J \& Rath D 2003 Effects of oviductal and cumulus cells on in vitro fertilization and embryo development of porcine oocytes fertilized with epididymal spermatozoa. Theriogenology 59 975-986.

Shimada A, Kikuchi K, Noguchi J, Akama K, Nakano M \& Kaneko H 2000 Protamine dissociation before decondensation of sperm nuclei during in vitro fertilization of pig oocytes. Journal of Reproduction and Fertility 120 247-256.

Sun FZ, Hoyland J, Huang X, Mason W \& Moor RM 1992 A comparison of intercellular changes in porcine eggs after fertilization and electroactivation. Development 115 947-956.

Suzuki K, Eriksson B, Shimizu H, Nagai T \& Rodriguez-Martinez H 2000 Effect of hyaluronan on monospermic penetration of porcine oocytes fertilized in vitro. International Journal of Andrology 23 $13-21$.

Tienthai P, Kjellen L, Pertoft H, Suzuki K \& Rodriguez-Martinez H 2000 Localization and quantitation of hyaluronan and sulfated glycosaminoglycans in the tissues and intraluminal fluid of the pig oviduct. Reproduction, Fertility and Development 12 173-182.

Wang WH, Abeydeera LR, Prather RS \& Day BN 1998 Morphologic comparison of ovulated and in vitro-matured porcine oocytes, with particular reference to polyspermy after in vitro fertilization. Molecular Reproduction and Development 49 308-316.

Wang WH, Machaty Z, Abeydeera LR, Prather RS \& Day BN 1999 Time course of cortical and zona reactions of pig oocytes upon intracellular calcium increase induced by thimerosal. Zygote 7 79-86.

Watson PF 1995 Recent developments and concepts in the cryopreservation of spermatozoa and the assessment of their postthawing function. Reproduction, Fertility and Development 7 $871-891$.

Wheeler MB, Clark SG \& Beebe DJ 2004 Developments in in vitro technologies for swine embryo production. Reproduction, Fertility and Development 16 15-25.

Wongsrikeao P, Karja NWK, Budiyanto A, Mtango NR, Murakami M, Nii M \& Otoi T 2004 Meiotic competence and DNA fragmentation of porcine oocytes from ovaries stored in various temperatures. Reproduction, Fertility and Development $\mathbf{1 6}$ 283-284 (Abstract).

Yoshida M 1987 In vitro fertilization of pig oocytes matured in vivo. Japanese Journal of Veterinary Science 49 711-718.

Received 29 April 2004

First decision 3 June 2004

Revised manuscript received 13 August 2004

Accepted 16 August 2004 